Article

\title{
The Nagoya Protocol: Fragmentation or Consolidation?
}

\section{Carmen Richerzhagen}

German Development Institute/Deutsches Institut für Entwicklungspolitik (DIE), Tulpenfeld 6, Bonn 53113, Germany; E-Mail: carmen.richerzhagen@die-gdi.de; Tel.: +49-228-94927-199;

Fax: +49-228-94927-130

Received: 23 December 2013; in revised form: 1 February 2014 / Accepted: 6 February 2014 / Published: 17 February 2014

\begin{abstract}
In October, 2010, a protocol on access and benefit-sharing (ABS) of genetic resources was adopted, the so-called Nagoya Protocol on Access to Genetic Resources and the Fair and Equitable Sharing of Benefits Arising from their Utilization to the Convention on Biological Diversity. Before the adoption of the Nagoya Protocol, the governance architecture of ABS was already characterized by a multifaceted institutional environment. The use of genetic resources is confronted with many issues (conservation, research and development, intellectual property rights, food security, health issues, climate change) that are governed by different institutions and agreements. The Nagoya Protocol contributes to increased fragmentation. However, the question arises whether this new regulatory framework can help to advance the implementation of the ABS provisions of the Convention on Biological Diversity (CBD). This paper attempts to find an answer to that question by following three analytical steps. First, it analyzes the causes of change against the background of theories of institutional change. Second, it aims to assess the typology of the architecture in order to find out if this new set of rules will contribute to a more synergistic, cooperative or conflictive architecture of ABS governance. Third, the paper looks at the problem of "fit" and identifies criteria that can be used to assess the new ABS governance architecture with regard to its effectiveness.
\end{abstract}

Keywords: Convention on Biological Diversity; Nagoya Protocol; institutional change

\section{Introduction}

At the 10th Conference of the Parties (COP) of the Convention on Biological Diversity (CBD), which took place in Nagoya in October, 2010, a new protocol on access and benefit-sharing (ABS) of 
genetic resources was adopted, the so-called Nagoya Protocol on Access to Genetic Resources and the Fair and Equitable Sharing of Benefits Arising from their Utilization to the Convention on Biological Diversity. The Protocol, setting the framework conditions for an international ABS regime, had been negotiated for more than six years. Following the Cartagena Protocol on biosafety in 2000, the Nagoya Protocol is the second protocol of the CBD and aims to support the implementation of the CBD's third objective: fair and equitable benefit-sharing. The CBD had been adopted in 1992 during the Rio conference. It aims at conserving and sustainably using biodiversity and realizing the fair and equitable share of the benefits that arise from the utilization of genetic resources. After Rio, the implementation of the $\mathrm{CBD}$ on the country level advanced quite slowly, and it became clear that its effectiveness relies on more than the diffusion of the CBD articles on the provider country level.

During the 1990s, the discussions within the CBD focused much on the dissatisfaction of the developing countries with the ABS regime. The group of megadiverse countries claimed for an international regime, arguing that provider countries are not capable of enforcing ABS without the support of user countries. This claim got strong support, due to the fact that there had been a quite high number of cases of misappropriation [1]. It is difficult to identify really successful ABS cases.

For example, a case in Ethiopia shows that even if providers and users come together with good intentions, the adoption of an ABS agreement can be very complicated and time consuming. Teff is a crop indigenous to Ethiopia, the country's major staple food, livestock forage and building material [2,3]. In 2004 a Dutch company, improving teff varieties and producing gluten-free flour, agreed on a memorandum of understanding with Ethiopia on benefit-sharing that offers Ethiopia joint ownership for teff varieties developed by the company [2]. It was agreed that Ethiopia receives as compensation $€ 10$ for every hectare of teff sewn outside of Ethiopia, that the company deposits five percent of net profits in a fund that it is used to support Ethiopian farmers and that the company deposits $€ 20,000$ annually in that fund until it starts to make a profit on teff [4]. The negotiations were quite complicated, since the agreement was signed before Ethiopia had adopted its own ABS law in 2006 and clarified institutional responsibility within Ethiopia. However, the company proceeded with its applications for intellectual property rights (IPRs) to grow its teff crop, as well as for the production of all products containing teff or teff flour. The company has been criticized by several NGOs (non-governmental organizations) regarding these applications. It won the Captain Hook Award for biopiracy in 2004, an award given by an NGO to companies, individuals or institutes that it considers to be biopirates [5]. However, the conflict was solved in the same year by including the Dutch ministry [3].

The call for an international regime was finally adopted by the WSSD (World Summit on Sustainable Development) in Johannesburg in 2002. The Johannesburg Plan of Implementation calls upon the parties of the CBD to negotiate an international regime to promote and safeguard the fair and equitable sharing of the benefits arising from the utilization of genetic resources [6]. The Bonn Guidelines, which were adopted in 2002 under the CBD, also address providers' and users' roles and responsibilities according to ABS. They propose a range of measures that user and provider countries should consider when implementing the CBD's ABS specifications. Usually, users are understood as those that use genetic resources and somehow receive benefits by the use (e.g., researchers, universities, pharmaceutical companies, etc.). Providers are countries, communities or individuals that take care of biodiversity and genetic resources and positively contribute to their provision. They hold different kinds of property rights over the concerned genetic resources (state, communal, private 
property rights or no property at all). User and provider countries are the political territories where users and providers act. They can be industrial, middle-income or developing countries. Many countries have both users and providers located in their countries.

The Bonn Guidelines are only voluntary guidelines. At COP7, the parties decided to mandate the Ad Hoc Open-ended Working Group on ABS to elaborate and negotiate an international regime on ABS with the aim of adopting instruments to effectively implement the provisions of Article 15 and Article 8(j) of the Convention and the three objectives of the Convention. At COP8, it was decided to continue the elaboration and negotiations of the international regime, and the ABS Working Group was instructed to complete its work at the earliest possible time before the COP10 in 2010. The negotiations ended in the Nagoya Protocol.

The Nagoya Protocol is an additional regulatory framework dealing with biodiversity conservation and ABS. It reflects a transformation of the original ABS regulations stipulated by the CBD. So far, there is hardly any literature focusing on change and institutional transformation processes with regard to the governance of biodiversity and of the environment in general. Young [7] makes a start and looks at change processes of social institutions that address human-environment-relations. He differs between five possible patterns of change of environmental and resource regimes to assess the quality of change: progressive development, punctual equilibrium, arrested development, diversion and collapse. Progressive development and punctual equilibrium are quite positive assessments of change. Here, regimes steadily advance or cope successfully with certain stress factors. Arrested development describes a situation in which a regime encounters obstacles that prevent development. Regimes that were created for one purpose, but are later redirected in a manner that runs counter purpose, are defined as diversion. The last category, collapse, describes a process that leads to the termination of a regime or at least to a dead letter. Now, the question arises under which category the Nagoya Protocol of the CBD falls. Has this new regulatory framework the potential to advance the implementation of the ABS provisions of the CBD (progressive development) or will it only add bureaucracy (arrested development)?

First, this paper analyzes the causes of change - the adoption of the protocol - against the background of theories of institutional change. Second, it aims to assess the typology of the institutional architecture in order to find out if this new set of rules will contribute to a more synergistic, cooperative or conflictive architecture of ABS governance. Third, the paper looks at the problem of "fit" and identifies criteria that can be used to assess the new ABS governance architecture with regard to its effectiveness.

\section{Status Quo}

Before the adoption of the Nagoya Protocol, the governance architecture of ABS was already characterized by a multifaceted institutional environment. The conservation and the use of genetic resources are confronted with many issues (e.g., conservation, research and development, intellectual property rights, food security, health issues) that are governed by different institutions and agreements. Genetic resources serve as an input for research and development in, e.g., the pharmaceutical sector to develop new drugs or in the agricultural sector to develop new crops, with a view toward the increase of productivity or addressing food security. Usually, such inventions will be patented, and intellectual property rights become an issue for genetic resources. 
The core institution that deals with the conservation of biodiversity and its sustainable use is the Convention on Biological Diversity (CBD), which was adopted in 1992 in Rio. Today (January, 2014), 193 countries are a party of the CBD. Only Andorra, the Holy Sea, South Sudan and the United States have not ratified the agreement.

The agreement covers all fields of biodiversity: ecosystems, species and genetic resources, existing in situ, as well as biological material, which has been stored in ex situ collections after the adoption of the CBD (CBD, Article 2) in 1993. The CBD links traditional conservation efforts to the economic goal of using biological resources for commercial purposes. Contrary to the classical protection concepts claiming for not using the resources at all, the CBD recognizes that biological resources can be conserved and used simultaneously, while ensuring their protection. According to its objectives, the agreement sets principles for the fair and equitable sharing of benefits arising from the use of genetic resources. To reach this goal, the CBD is based on a bilateral system of exchange of genetic resources and compensations, called access and benefit-sharing (ABS). ABS establishes specialized payments for an ecosystem services (PES) scheme that attempts to monetize the commercial value of biodiversity in research and development. Therefore, it is a market-based approach and internalizes the private commercial value of genetic resources, which is, however, only a partial value within a bundle of values determining the social benefits of biodiversity. Nevertheless, under this concept, monetary and non-monetary benefits from users (i.e., pharmaceutical companies, agribusiness, cosmetic industries, etc.) to providers are thought to provide conservation incentives in provider countries.

There exist several other multilateral environmental agreements that are biodiversity related, such as, for example, the Convention on International Trade in Endangered Species of Wild Fauna and Flora (CITES), the Convention on the Conservation of Migratory Species of Wild Animals (CMS), the Ramsar (Wetland) Convention, the World Heritage Convention (WHC), the Food and Agricultural Organization (FAO) International Treaty on Plant Genetic Resources for Food and Agriculture (ITPGRFA), as well as the United Nations Framework Convention on Climate Change (UNFCCC) and the United Nations Convention to Combat Desertification (UNCCD). Whereas these conventions deal with specific categories of biodiversity or with other biodiversity-related issues, the CBD is the most comprehensive and inclusive international agreement on the conservation of species and ecosystems. For example, CITES aims to ensure that international trade in specimens of wild animals and plants does not threaten their survival. CITES controls the trade of selected species by monitoring imports, exports and re-exports of the species through a licensing system. For many years, it has been discussed whether a forest convention is needed to deal with deforestation issues. So far, forest issues are discussed within the $\mathrm{CBD}$ and the United Nations Framework Convention on Climate Change (UNFCCC), where forests as carbon sinks play an increasing role. ABS does not play a role in these agreements.

The ITPGRFA of the Food and Agricultural Organization (FAO) is the only agreement that comes very close to the CBD with regard to the regulatory framework. It was negotiated to complement the ABS regulations of the CBD for a certain category of genetic resources. Its objectives are quite similar to the ABS regulations of the $\mathrm{CBD}$, but limited to plant genetic resources for food and agriculture. The treaty applies to 35 crops and 80 forages essential for food security. It aims at the conservation and sustainable management of plant genetic resources, as well as the fair and equitable sharing of the benefits arising from their use (ITPGRFA, Article 1.1). As with the CBD, the ITPGRFA recognizes the 
sovereign rights of states over their genetic resources and the rights of the national governments to determine access to those resources resting with national governments (ITPGRFA, Article 10.1). However, the ITPGR establishes an absolutely different benefit-sharing system. The key component of the treaty is a multilateral system of ABS applying to the mentioned list. Users of these genetic resources have to contribute into a fund, and the money is distributed to different providers through the FAO.

The rationale behind a separate regulatory framework for these genetic resources lies in their distinct characteristics, especially the attribution of the country of origin and the need for an unrestricted access to a wide genetic base for future crop improvements against the background of sustainable agriculture and food security. The ITPGRFA is much younger than the CBD. It was adopted in 2001 and entered into force in 2004. The broad distribution and storage of already collected material, as well as the experiences with ABS in the CBD probably contributed to the fact that governments agreed on a multilateral system.

The CBD system, the acquisition of genetic resources on a case-by-case bilateral basis, often involves high transaction costs. Besides, the CBD leaves the issue of ex situ collections harboring material that was collected before the adoption of the convention unsettled [8]. However, under the $\mathrm{CBD}$, there is still a direct link between users and providers, which can play an important role with regard to incentives.

In order to support the communication among the biodiversity-related conventions and enhance coherence and cooperation, a liaison group has been established between the heads of the secretariats of the six biodiversity-related conventions.

Further agreements or institutions that touch on CBD issues are, for example, the United Nations Educational, Scientific and Cultural Organization (UNESCO), the World Trade Organization (WTO), the World Intellectual Property Organization (WIPO) and the World Health Organization (WHO). Conflicts between the CBD and these institutions and their agreements can arise indirectly, due to conflicts of the goals, but they can also reinforce each other. These institutions follow entirely different objectives. For example, the WTO and WIPO seek for the harmonization and the strengthening of intellectual property rights regulations, whereas the $\mathrm{CBD}$ aims at the conservation of biodiversity.

However, despite the fragmented architecture of biodiversity governance, the CBD plays a central role in ABS governance. The inclusion of the main stakeholders (i.e., governments, NGOs, indigenous communities, private actors and science), its broad mandate and a well-structured and dynamic negotiation process by a functioning secretariat contribute to its effectiveness and make it to the most important convention on the protection of biodiversity.

\section{Causes of Institutional Dynamics}

The Nagoya Protocol is the result of a long negotiation process towards an international regime for ABS. What are the reasons for the negotiations of an international regime and the adoption of a new protocol? So far, much research has been done on the conditions under which multilateral agreements were established or how they function. Only little research has addressed the question of how such agreements evolve over time in the context of fragmentation or consolidation. Looking at it from an institutional transformation perspective provides different explanatory variables that I will analyze in this article. There exists a bunch of institutional change literature, but most of it focuses on economic 
systems. The institutional dynamics of environmental and resource regimes is so far underdeveloped [9]. In this section, I try to explore what determinants of institutional dynamics, derived by economic theory on institutional change, can be applied to the development of the CBD and the adoption of the Nagoya Protocol.

Within economic theory, there exist different perspectives, and theory strands on institutional change. Usually, institutional change is a mixture of the following different forms. Functional theory is based on the concept of bounded rationality and assumes some given opportunity to improve an individual situation (e.g., increase wealth, change of preferences) by institutional change. Thereby, bounded rational utility-maximizing individuals shape formal institutions [10]. According to North [11], institutions "are the rules of the game in a society, or more formally, are the humanly devised constraints that shape human interaction". Organizations are seen as the player of these games [12]. He finds that new institutions arise (i.e., institutional change occurs) when groups in society perceive a possibility of availing themselves of profits that cannot be realized under the former institutional conditions. Williamson [13] argues that a change in transaction costs may lead to institutional change. Actors seek arrangements that help them to reduce transactions costs [10].

Power theories complement functional theories by addressing the role of individuals and groups depending on their bargaining power play for change [10]. If change actually occurs, it depends on the power and influence certain groups have on the process. Often, institutions are supported by groups that have an interest in preserving the status quo, which can impede institutional change and enable inefficient institutions to stay in place [14]. Furthermore, the bounded rationality may prevent institutional change. Some actors may under- or over-estimate the consequences of institutional change [15].

Isomorphic theories characterize institutional change as a path-dependent process, because past agreements on institutions still present the framework for responding to the changes [16]. According to North [12], economies of scope, complementarities and network externalities of an institutional matrix make institutional change path dependent. Organizations owe their existence to the institutional matrix and have an interest to maintain the institutional structure, thus assuring path dependence [17]. Another argument put forward to explain path dependency is uncertainty [10]. Under uncertainty, individuals or groups tend to orientate them towards the known.

The last category of theories deals with more endogenous factors of learning. Besides changes in the environment, the acquisition of learning and skills can induce change [18]. According to North, "the rate of learning determines the speed of economic change, the kind of learning determines the direction of economic change" [17]. Siebenhüner and Suplie understand institutional learning "as a process in which individual or collective actors acquire knowledge that leads to a change in their behavior and results in changed institutional arrangements" [19]. They identify the following learning processes as highly influential on ABS: (i) the existence of actor coalitions; (ii) the establishment of reflexive mechanisms that gather and assess the existing knowledge and prepare new decisions; (iii) a functioning communication and process facilitation infrastructure; (iv) predominantly productive conflicts; and (v) international negotiation dynamics that pressurize the processes in the policy arena [19].

The literature on institutional change suggests that both exogenous and endogenous causes (i.e., the acquisition of learning and skills) as drivers of institutional change. However, the most observed institutional changes are induced by external factors (i.e., changes in prices). 
Institutional change can be induced or be imposed. An induced change refers to a change that is voluntary initiated by individuals or a group of people with the prospect of increasing benefits, whereas an imposed change is driven by laws and regulations [20]. Many authors view institutional change as a collective action process in which individuals or groups initiate institutional change for their own benefit [14]. In that case, the change would be induced.

As shown, institutional theories deliver different approaches to analyze change processes. How can these theories be applied to the developments under the CBD and the adoption of the Nagoya Protocol?

The institutional change within the CBD and the development of the Nagoya Protocol can be explained by mainly three, in theory, described approaches: (i) the prospects of improving the situation and realizing profits; (ii) the power and influence certain groups have on the process; and (iii) the tendency towards path dependency. First of all, some actors (e.g., developing countries) are assumed to reduce transaction costs and improve their situation by adding a new regulatory framework to the CBD. The development of the Nagoya Protocol has been a collective action process within the CBD, although some groups pushed for it more than others. However, the rules are explicitly specified by a collective political entity - the parties of the CBD [14]. According to the consensus principle, all parties of the CBD have to agree with the decisions taken during a COP. The adoption of the decisions usually precedes a long bargaining period in order to change the rules for their own benefit. At the same time, the Nagoya Protocol is path dependent. The Nagoya Protocol has been negotiated in the framework of the CBD. It aims to serve the same objectives and is, therefore, restricted regarding its maneuvering room. However, at the same time, the close relationship guarantees coherence and strength.

Some actors hoped to be better off after the adoption of the Protocol and the change is induced. The negotiations on an international regime can be attributed to developing countries. Whereas certain issues in the $\mathrm{CBD}$, e.g., increase of protected areas, are pushed by industrialized countries (in particular, EU member countries), ABS topics (as well as financial issues) are mainly driven by developing countries' dissatisfaction. Developing countries were displeased with the implementation of $\mathrm{ABS}$. In the $\mathrm{CBD}$, the ABS regulations are very provider-orientated (i.e., most provisions need to be implemented by providers) and put much burden on developing countries, whereas the activities of users were not monitored and controlled and the provider countries usually lack the capacity to do so. Many reports on misappropriation prove this. Therefore, developing countries have been claiming for a more balanced, international regime that integrates users much more in the process and that addresses the evident weaknesses. Usually, provider countries only provide the resources. Further steps of development and research take place in the user countries. Therefore, provider countries are unable to track the process and monitor the use of the provided genetic material. Other monitoring mechanisms are missing. In the past 20 years the ABS concepts have been in place, only very few benefits have been shared with developing countries. Most of them are non-monetary benefits [4]. By negotiating and adopting an international regime with strong compliance elements, developing countries hoped to receive fair and more benefits arising from the use of genetic resources.

Second, bargaining powers shaped the outcome. The negotiations on the international regime were a long and complicated process. It took more than six years to agree on a text. For many years, the industrialized countries have been resistant in negotiating a legally binding international agreement on ABS. They opted for voluntary guidelines or an international regime comprising legally binding and non-legally binding instruments. In March 2010, during a working group meeting, all parties adopted a 
document containing the text of a draft protocol with the aim to adopt a legally binding protocol. However, in the end, the negotiations were still characterized by a deep division between developing and developed countries, with Norway providing a middle ground, and it was stated that the document was not negotiated, but put together by the chairs of the meeting, and that further amendments are most likely. Controversial discussed were the following issues: the scope of the Protocol, standards for granting access, obligations for monitoring, technology transfer, financial mechanisms and the relationship between the Protocol and other international agreements [21].

The negotiations in Nagoya were very tough. Many developing countries feel excluded from the final steps. During the last days of the negotiations, the EU and Brazil held secret negotiations supported by Japan, who was the host of the meeting and highly interested in bringing the COP to a successful end. Brazil was the former leader of the Like-minded Megadiverse Countries and other developing countries. At some point during the negotiations, developing countries had threatened not to agree on issues if the ABS protocol fails to be adopted (e.g., strategic and resource mobilization plan). However, since Brazil had changed its opinion and preferred to adopt a weak protocol, the coalition of developing countries broke down. After the proposal of the EU, Brazil and Japan was presented, much pressure was put on other developing countries to agree, which they finally did. The persistence of the Japanese government and a high willingness to compromise on either side helped to overcome the blockade. However, some countries (e.g., Venezuela, Brazil) criticized the outcome and the process under which the Protocol was finally adopted [22].

Third, it is not surprising that the development of the Nagoya can be described as path dependent. The Nagoya Protocol was negotiated and will be implemented under the CBD. The CBD process is internationally regarded as a quite successful process, compared to the negotiations under the UNFCCC or the UNCCCD. Therefore, all the regulations, procedures and new institutions are closely oriented towards the CBD (see Sections 4 and 5).

\section{Degree of Fragmentation}

With the Nagoya Protocol, an additional regulatory framework is adopted within the CBD and enhances fragmentation. According to Biermann et al., fragmentation is considered to be value free [23]. It can have positive and negative impacts on the governance of selected issue areas. The literature differentiates three levels of fragmentation of governance architectures according to the level of institutional integration, the existence of norm conflicts and the actor constellation [23]. Synergistic fragmentation is characterized by a high degree of integration (e.g., one core institution is responsible for the problem issue and closely cooperates with other relevant institutions), by integrated norms and by the inclusion of all relevant actors. Cooperative fragmentation is understood as a form in which different core institutions and decision making are loosely integrated procedures, but in which an ambiguous relationship between the principles of different institutions exists. Some actors are not integrated. Conflictive fragmentation describes a situation in which different core institutions are hardly connected, where we have a conflicting set of principles, norms and rules and in which major actors support different institutions [23].

Even before the adoption of the Nagoya Protocol, the governance architecture of ABS was already characterized by a multifaceted institutional environment. With the Nagoya Protocol, a new regulatory 
framework is added to this fragmentation. However, the question remains how we can assess the role of the Protocol within this context.

Applying the given framework to the Nagoya Protocol suggests that the relationship between the $\mathrm{CBD}$ and the protocol describes a cooperative or even a synergistic fragmentation, due to the following reasons. The Nagoya Protocol was negotiated in the framework of the CBD and finalized in Nagoya, October 2010. The Nagoya Protocol is embedded in the existing framework of the CBD and supports its objectives (Nagoya Protocol, Article 1). The Secretariat of the CBD is responsible for the administration of the Nagoya Protocol. The meetings of parties (MOP) will take place simultaneously with the COP (as is the case of the MOP of the Cartagena Protocol).

The financial resources are provided through the same channels. In May 2011, the Global Environment Facility (GEF) established the Nagoya Protocol Implementation Fund. The CBD Secretariat has been approved as the operator of the fund. Japan provides about US \$12 million to the fund; France, Norway and Switzerland also announced contributions. GEF is the designated institution operating the financial mechanism of the CBD.

All these aspects suggest that the Protocol is very synergistic. In the end, all the parties of the CBD had to agree on the negotiated text before it was adopted. Therefore, it can be expected that the protocol is consistent with the CBD.

However, some authors have already analyzed that conflicts may appear [24,25]. First of all, it is criticized that the final text of the protocol was not arrived at through transparent negotiations. The way to the protocol was a very long and complicated process with many setbacks. In 2004, the parties of the CBD mandated the Ad Hoc Open-ended Working Group on Access and Benefit-sharing to negotiate an international regime on ABS, and in 2008, they set a deadline to finish the negotiations by 2010. During that time, the group met eleven times from 2005 to 2010, and the process was seen as open and democratic. So far, the negotiations were difficult, but quite transparent.

During the latest COP in Nagoya, observers gained the impression that the negotiations would probably fail. The controversies between the parties seemed to be unsolved until the end. However, during the last two days, the EU, Brazil (representing the Group of Like-minded Megadiverse Countries (LMMC)) and Japan, with the support of the Secretariat of the CBD, prepared the draft protocol that is mainly based on the negotiated text, but that also contains new elements (e.g., an article on a multilateral benefit-sharing mechanism) that have not been negotiated before. Some countries were overwhelmed by these developments and felt under great pressure to agree, which they finally did [24].

Looking at the text of the Protocol, it becomes clear that it focuses on the areas of access, benefit-sharing and compliance. The industrialized countries put emphasis on facilitated access, whereas developing countries stressed the need for a better mechanism to realize benefit-sharing and compliance. In the view of some developing country negotiators, several provisions of the new Protocol only repeat existing provisions in the CBD, indicating a conservative path dependency. They have therefore no impact and bring no change. Some provisions go beyond the CBD and establish new obligations, such as, for example, on access and pathogens. Many provisions of the Protocol remain unclear and require further specification by the COP/MOP of the Protocol [24]. In the end, it seems that user countries' interests are better reflected in the Protocol than developing countries' interests. In return, a Protocol was adopted. This would have probably never been possible without such concessions. 
The Protocol needs to be signed and ratified by the countries that want to implement it. Only if more than 50 countries have ratified it will the Protocol enter into force. There might be the possibility that the Protocol will have fewer signatories than the Convention itself. For example, the CBD has 193 parties, whereas the Cartagena Protocol has only 166 parties. Some countries may not sign the Protocol because they do not agree with the terms; others may just lack the capacity to implement it. If the parties of the Nagoya Protocol significantly deviate from the parties of the CBD, conflicts may arise (e.g., like the case of the Kyoto Protocol: the USA refused to ratify it). Today (January, 2014), the Nagoya Protocol has 92 signatures and 29 ratifications. Although at first sight, the adoption of the Protocol can be described as synergetic fragmentation, these concerns may overshadow this optimism.

\section{The Problem of Fit}

When does change lead to improved performance? Can the Nagoya Protocol address the weaknesses of the old system? According to Biermann, et al. [23], I just described the new ABS governance architecture as synergistic. However, some worries remain, due to the concerns already raised.

To assess the effectiveness of the new system in comparison to the old, one can even give a better answer. According to Young [26], the effectiveness of environmental regimes depends on the "fit", i.e., on the way institutions fit the biophysical world and its problems. Biodiversity and their genetic resources have specific characteristics that need to be considered when looking for institutional solutions to stop their degradation. In the case of ABS, in which genetic resources are used as input for research and development in different industrial sectors, the question of "fit" cannot be limited to the compatibility of ecosystems and institutions established to manage the impact that humans have on ecosystems. The analysis of the "fit" needs to take into account the specific characteristics genetic resources reveal when they enter the production process.

The Nagoya Protocol has been developed to address both the still existing market failures that the ABS concept so far could not abolish and new weaknesses that arise by the concept itself. Biodiversity declines due to classic market failures. It produces positive externalities (e.g., as input in research and development, climate stabilization, food) for the society that are not taken into consideration by private actors. Consequently, investments in biodiversity are too low to sustain the resource. Furthermore, the market for biodiversity fails, due to policy and institutional failures [27]. Appropriate policies and institutions are missing, despite the increased conservation activities in the past 20 years.

The ABS concept of the CBD tried to address both market and institutional failures. By assigning the rights of sovereignty to provider countries and requiring fair and equitable benefit-sharing, it attempts to establish a market for biodiversity [28]. According to economic theory, the trade of genetic resources will lead to an internalization of biodiversity's benefits. However, the results are quite limited, and certain factors are hindering the concept from functioning. Until now, the decline of biodiversity could not be stopped, and only a few benefits have been received by provider countries. Providers even criticize that their material is still being used without any compensation. Users complain about restrictive access and use opportunities. Economic theory can help to identify the reasons for the on-going failure and to analyze why the concept has failed so far. Externalities, transaction costs, information asymmetries and imperfect competition in the market for genetic 
resources prevent it from functioning. Derived from economic theories, six critical factors determine the effectiveness of ABS regimes before the Nagoya Protocol was adopted [4]. However, these factors are not limited to the CBD itself and can also be applied to any ABS regime. Therefore, they can also be applied to the new ABS governance structure after the adoption of the Nagoya Protocol. The critical factors deal with property rights, asymmetric information between contracting partners, time lags, administrative complexity, the governance and transaction environment and the structure of the market of genetic resources. Depending on their specific configuration and the countermeasures in place, they can have either a positive or a negative influence on the outcome of ABS negotiations and contracts. Although discussed here as single determinants, they may interact, as well: measures for positively addressing one critical factor can have negative implications for another factor. For example, increased monitoring and enforcement can reduce information deficiencies and secure property rights on the one hand, while also increasing administrative complexity on the other.

\subsection{Property Rights and Intellectual Property Rights (IPRs)}

Property rights, including intellectual property rights (IPRs), are the most relevant critical factor in the ABS concept. We can find different property rights along the value chain of the utilization of genetic resources: private or common property rights over land and biological resources at the local level, state sovereignty over natural resources at the national level and the intellectual property rights of users of genetic resources over products derived from genetic resources.

In reality, however, we observe an asymmetry in the allocation of property rights along the value chain of genetic resources. The strength of property rights increases with economic market value. The assignment of property rights on the local level is currently left up to the national governments and is in most cases very weak. However, according to property rights theory, private property rights contribute to an efficient allocation of resources and increase social welfare [29]. As long as externalities still exist because property rights are not well defined, the marketing of genetic resources will fail. Besides private property rights, a strand of economic theory suggests that common property allows for sustainable resource use [30].

The CBD stipulates that governments have relatively strong rights over their biological resources. IPRs, on the other hand, take effect at the other end of the value chain and provide users with strong rights after a product has been developed. In general, IPRs protect products for about 20 years and assure the IPR holder of long-term profits. The role of IPRs in innovation, economic growth and resource conservation has been debated for some time. The general notion has been that developing countries tend to lose by strong IPR protection and that this is the reason why many developing countries have refused to introduce increased IPR protection unless forced to do so by international agreements [31].

Strong IPRs on the user side require a counterbalance on the local level. Strong property rights on the user side and weak rights on the provider side lead to market failure and further resource destruction. Two options exist for strengthening the property rights of resource managers. On the one hand, national governments can ensure that the local level participates in the property rights over biodiversity and the benefits that arise from their use. On the other hand, international and national patent law requires the disclosure of the origin of genetic resources when IPRs are granted. 
It was hoped that the Nagoya Protocol would address the imbalance arising from property rights distribution. Within the CBD, the imbalance can be addressed from both sides: strengthening the providers or making sure that users share parts of their rights and benefits. The Protocol has strengthened the local level by asking the parties to take legislative, administrative or policy measures to ensure that benefits arising from the utilization of genetic resources that are held by indigenous and local communities are shared in a fair and equitable way with the communities concerned (Nagoya Protocol, Article 5.2).

During the negotiations, it was in the developing countries' interest to establish better compliance mechanisms to address their lack of capacity to control the use of the provided material. Finally, four articles deal with compliance issues (Nagoya Protocol, Articles 15-18). However, the compliance section of the Protocol is rather weak. It does not specify any measures that user countries should establish to address compliance. They are only required to implement "appropriate, effective and proportionate measures to address situations of non-compliance" in user countries (Nagoya Protocol, Articles 15.2 and 16.2).

\subsection{Asymmetric Information}

Asymmetric information increases transaction costs and, therefore, has a negative impact on the outcome of negotiations. Information deficiency may be present on both the user and provider side in the form of a principal-agent problem. Foremost, providers have information deficiencies regarding the expected benefits to be derived from genetic resources and the factual utilization of the materials once users have obtained them. In many cases, providers cannot estimate the value of the expected benefits and, therefore, ask for unrealistic benefits during negotiations. As a consequence, users and providers cannot agree on a contract. At a later stage, providers cannot track how the provided material is used. Worried about unapproved use, provider countries then over-regulate use and deny access.

Users, on the other hand, may lack information on the exclusivity of the provided material, the quality of the material and the utilization of the received benefits. They may then react with a country substitution, i.e., they look for another provider who offers more complete information. All these scenarios lead to decreased access, a low level of benefit-sharing and conservation activities. Information deficiencies can be addressed by measures that provide additional information and overcome insecurity or by flexible contracts [13].

As it is for property rights, compliance is the main issue in the Nagoya Protocol, which addresses the uncertainty arising from asymmetric information. In order to ensure compliance and monitor the utilization of genetic resources, countries should establish at least one checkpoint. It is not specified how such a checkpoint should look. In the negotiations, developing countries have put forward many proposals on the disclosure of origin/compliance as a compliance mechanism. The first proposal regarding the disclosure of the country of origin emerged in 1994 jointly with the proposal for certificates of origin, which were later named certificates of compliance. It tried to link the IPR system and ABS and put forward the idea of requiring the disclosure of origin in patent applications [32]. The idea is that an inventor who applies for a patent, which is based on the utilization of genetic resources, has to provide additional information on the material's source or even proof of its legal acquisition [33]. The discussions on disclosure requirements were not limited to the CBD. Some 
countries proposed changes to the TRIPS (Trade Related Aspects of Intellectual Property Rights) agreement of the WTO to include the disclosure of origin into the applied rules of the disclosure of inventions when a patent is applied for [25]. Certificates of compliance were seen as instruments that can help to implement the disclosure requirement by helping to monitor the flow of the genetic material. The idea behind them was that certificates can travel with the resources, like a passport, and that at certain checkpoints, the appropriate use of the material can be controlled. The developing countries could not enforce their claim. Many user countries (e.g., Canada and Australia) refused the proposal. Furthermore, no sanction mechanisms have been agreed on to remedy the non-disclosure of information at checkpoints [25].

\subsection{Administrative Complexity}

Administrative complexity determines the way transactions are carried out. It concerns bureaucratic procedures in the administrations and the adjustment of these procedures to the needs of the "clients" [34]. Administrative complexity is closely linked to institutional capability. A low level of institutional capacity increases administrative complexity and transaction costs. This is the case in many developing countries. Competent, multifunctional institutions in provider countries are required to design and allocate rights, manage conservation areas, coordinate activities, negotiate ABS contracts, control compliance and sanction misappropriation regarding the use of genetic resources. This, in turn, requires funding for the establishment and maintenance of such institutions. The Nagoya Protocol addresses the issue of complexity by formulating comprehensive regulations for the access phase. It requests provider countries to provide clear regulations on ABS and cost-effective procedures for facilitating user access (Nagoya Protocol, Article 6.3f). It is required that provider countries issue a permit, which can serve as evidence of compliance (Nagoya Protocol, Articles 17.2-17.4). This is then submitted to the ABS Clearing-House and functions as a certificate (Nagoya Protocol, Article 6.3e). Furthermore, the Protocol requires the parties to designate focal points and national competent authorities and to inform the Secretariat about it (Nagoya Protocol, Article 13).

\subsection{Governance and Transaction Environment}

The transaction environment plays an important role in transaction costs that arise in the access phase of ABS. This was also one result of a survey that asked potential users in Germany about the main problems regarding the acquisition of genetic resources [35]. In particular, the general transaction environment is important if users collect the material themselves in provider countries.

Good governance in a country positively influences the transaction environment. The concept of good governance is mainly applied in development policy. The World Bank's Governance Indicators measure six dimensions of governance: voice and accountability, political stability and absence of violence, government effectiveness, regulatory quality, rule of law and control of corruption [36]. However, the dimensions are very wide ranging and only shed some light on the general governance conditions. To understand how they impact the effectiveness of ABS, we need to define ABS-specific indicators derived from the general dimensions. It is important whether the provider country has already implemented clear-cut ABS regulations, has signed the Nagoya Protocol and shows the political will to promote ABS implementation. If ABS legislation is weak or not even implemented, 
users can react with country substitution or underinvestment in genetic resources. The strengthening of institutions and political systems, as well as the support of the formulation of laws facilitates the development of good governance. Here, the Nagoya Protocol provides some support by setting up a clearing-house mechanism.

\subsection{Time Lags}

Time lags degrade the incentive structure of contracts, since the transactions, the provision of genetic material and the development of a product are not simultaneous. If the time frames between the collection of genetic material and the flow of benefits are too long, no incentives for conservation exist.

The variation among industry sectors regarding the time it takes to develop a marketable product from a natural sample is enormous, as is the probability that it will be successful. In the pharmaceutical sector, 10 to 15 years of research and development are necessary to discover and develop a drug. The probability of success varies from one in 5000 to one in 10,000 . In the botanical medicine sector, the process may take less than two years. However, this sector is still regarded as a niche sector. In the agricultural sector, eight to 15 years may be required to develop a new plant variety, and development of a new chemical pesticide may take from eight to 14 years, whereas a biocontrol agent can be developed within two to five years [37].

Experience has shown that users of genetic resources are not willing to pay adequate compensation before a product is developed and distributed to the market. However, income substitutions, which change economic activities and limit actions damaging to biodiversity, must be financed directly in order to be effective and not 15 years later. Otherwise, benefit-sharing will fail as a means of instituting incentives for the conservation of biodiversity.

A fund, as a payment scheme, can address the problems arising from time lags. Such a multilateral fund is considered in the Nagoya Protocol. The Protocol requires future work to consider the need and the modalities of a global multilateral benefit-sharing mechanism. So far, proposals, submitted by the African countries since 2007, on a multilateral system within the CBD had not been seriously discussed and negotiated. According to the Protocol, the multilateral mechanism should be applied in transboundary situations and in situations in which it is not possible to grant or obtain prior informed consent. However, taking the negotiations on the Nagoya Protocol as an example, the negotiations of such a fund will probably take very long.

\subsection{Market Structure}

The market structure has a strong impact on negotiations and their outcome. To reach fair and equitable benefit-sharing, negotiations on ABS have to be undertaken by equal partners. In the case that change renegotiations have to take place, contracting partners should be on par with each other. Due to market conditions, however, provider countries are in a weaker position. The market is dominated by a small number of large-scale buyers and can, thus, be described as a form of oligopsonistic competition. In past years, mergers between agro-chemical, agro-seed and pharmaceutical firms have created large, global life-science companies and strengthened their position in the market [38]. Although the industry argues that genetic resources have become less important, recent data indicate that in Germany, for example, users expect to constantly use genetic resources or even expand their 
use [35]. However, ex situ collections, which provide material collected before the CBD was adopted, as well as the existence of identical genetic resources in neighboring countries, offer alternatives for users and weaken the bargaining position of single providers. Restricted by the scope of the CBD, the Nagoya Protocol does not offer anything to address the problem arising out of the market structure.

\section{Conclusions}

The Nagoya Protocol is a new protocol under CBD. The process of negotiations was slow and difficult, but in the end, a new text came out that had not been expected. According to Young's characterization of regime change, the Protocol can probably be seen as a progressive, but very path-dependent development. It widens and advances the regulation of the CBD to some extent, but many developing countries are disappointed, because they hoped to get more and have the feeling that the industrialized countries came out on top. For a comprehensive assessment, it is still too early. The meaning of many articles in the Protocol is still unclear and will only be clarified when national implementation starts, and the negotiations of the Protocol in the Meeting of the Parties will go on. However, it can be said that the CBD and the Nagoya Protocol are quite synergistic. They comprise the same actors, apply the same rules and procedures and have the same objectives.

Economic theory on institutional change provides many explanatory variables on institutional change. Some of them can be applied to explain the change of the biodiversity regime. The main reason that the Protocol had been negotiated is that some actors hoped to be better off after the adoption of the Protocol. However, the quality of the final text is very much influenced by the bargaining power of single actors. In the end, those that hoped to be better off are not satisfied with the results.

Nevertheless, assessing the effectiveness of the new regime makes clear that the change towards a Protocol leads to an improved situation. Some of the critical factors (property rights, asymmetric information between contracting partners, time lags, administrative complexity, governance and transaction environment and the structure of the market of genetic resources) are addressed positively, and existing weaknesses can be abolished. Some of the existing problems will remain, but none of the critical factors will be affected negatively. However, the real consequences of the Protocol depend on its implementation at the national level and by its clarification through up-coming meetings.

\section{Conflicts of Interest}

The author declares no conflict of interest.

\section{References}

1. Robinson, D.F. Confronting Biopiracy: Challenges, Cases and International Debates; Earthscan: London, UK, 2010.

2. Feyissa, R. Farmers' Rights in Ethiopia. A Case Study. Background Study 5; Fridtjof Nansens Institute, GTZ: Lysaker, Norway, 2006.

3. Secretariat of the Convention on Biodiversity (SCBD). Access and Benefit-Sharing in Practice: Trends in Partnerships Across Sectors; SCBD: Montreal, Canada, 2008. 
4. Richerzhagen, C. Protecting Biological Diversity-The Effectiveness of Access and Benefit-Sharing Regimes; Routledge: New York, NY, USA, 2010.

5. Coalition Against Biopiracy Captain Hook Awards for Biopiracy. Available online: http://www.etcgroup.org/node/126 (accessed on 2 January 2014).

6. United Nations (UN). Plan of implementation of the world summit on sustainable development. In Report of the World Summit on Sustainable Development-A/CONF.199/20*; United Nations: Johannesburg, South Africa, 2002.

7. Young, O.R. Institutional Dynamics: Emergent Patterns in international Environmental Governance; Massachusetts Institute of Technology: Cambridge, MA, USA, 2010.

8. Moore, G.; Tymowski, W. Explanatory Guide to the International Treaty on Plant Genetic Resources for Food and Agriculture; IUCN: Gland, Switzerland; Cambridge, UK, 2005; Volume 57, p. 226.

9. Young, O.R. Institutional dynamics: Resilience, vulnerability and adaptation in environmental and resource regimes. Glob. Environ. Chang. 2010, 20, 378-385.

10. Schmid, A.A. Conflict and Cooperation: Institutional and Behavioral Economics; Blackwell: Oxford, UK, 2004.

11. North, D.C. Institutions, Institutional Change and Economic Performance (Political Economy of Institutions and Decisions); Cambridge University Press: Cambridge, UK, 1990; p. 159.

12. North, D.C. The Process of Economic Change; World Institute for Development Economics Research: Helsinki, Finland, 1997.

13. Williamson, O.E. The Economic Institutions of Capitalism: Firms, Markets, Relational Contracting; Free Press: New York, NY, USA, 1985; p. 450.

14. Kingston, C.; Caballero, G. Comparing theories of institutional change. J. Inst. Econ. 2009, 5, 151-180.

15. Ostrom, E. Understanding Institutional Diversity; Princeton University Press: Princeton, NJ, USA, 2005.

16. Libecap, G.D. Contracting for Property Rights; Cambridge University Press: Cambridge, UK, 1989.

17. North, D.C. The New Institutional Economics and Development; Economic History 9309002; EconWPA: St. Louis, MI, USA, 1993.

18. North, D.C. Institutional Change: A Framework of Analysis; Economic History 9412001, EconWPA: St. Louis, MI, USA, 1994.

19. Siebenhüner, B.; Suplie, J. Implementing the access and benefit sharing provisions of the CBD: A case for institutional learning. Ecol. Econ. 2005, 53, 507-522.

20. Lin, J.Y. An economic theory of institutional change: Induced and imposed change. Cato J. 1989, 9, 1-33.

21. Ling, C.Y. Rocky road still ahead for ABS protocol. Available online: http://www.twnside.org.sg/ title2/intellectual_property/info.service/2010/ipr.info.100401.htm (accessed on 6 June 2013).

22. Stefan Jungcurt, T.K.; Morgera, E.; Recio, E.; Schabus, N.; Tsioumani, E. Summary of the Tenth Meeting of the Conference of the Parties to the Convention on Biological Diversity; Earth Negotiations Bulletin, Volume 9, No. 544; International Institute for Sustainable Development: New York, NY, USA, 2010. 
23. Biermann, F.; Pattberg, P.; Asselt, H.V. The fragmentation of global governance architectures: A framework for analysis. Glob. Environ. Politics 2009, 9, 14-40.

24. Nijar, G.S. The Nagoya Protocol on Access and Benefit Sharing of Genetic Resources-An Analysis; Working Paper 36; South Center: Geneva, Switzerland, 2011.

25. Joseph, R.K. International regime on access and benefit sharing: Where are we now? Asian Biotechnol. Dev. Rev. 2010, 12, 77-94.

26. Young, O.R. The Institutional Dimensions of Environmental Change. Fit, Interplay, and Scale; Massachusettes Institute of Technology: Cambridge, MA, USA, 2002.

27. Swanson, T.M. Why does biodiversity decline? The analysis of forces for global change. In Economics and Ecology of Biodiversity Decline: The Forces Driving Global Change; Swanson, T.M., Ed.; Cambridge University Press: Cambridge, UK, 1995; pp. 1-10.

28. Organisation for Economic Cooperation and Development (OECD). Economic Issues in Access and Benefit Sharing of Genetic Resources: A Framework for Analysis; OECD: Paris, Franch, 2003; p. 58.

29. Richter, R.; Furubotn, E. Neue Institutionenökonomik; Mohr: Tübingen, Germany, 1996; p. 555.

30. Ostrom, E.; Burger, J.; Field, C.B.; Norgaard, R.B.; Policansky, D. Revisiting the commons: Local lessons, global challenges. Science 1999, 284, 278-282.

31. Chen, Y.; Puttitanun, T. Intellectual property rights and innovation in developing countries. $J$. Dev. Econ. 2005, 78, 474-493.

32. Barber, C.V.; Johnston, S.; Tobin, B. User Measures Options for Developing Measures in User Countries to Implement the Access and Benefit-Sharing Provisions of the Convention on Biological Diversity, 2nd ed; United Nations University: Tokyo, Japan, 2003; Volume 11, p. 44.

33. Tobin, B. Certificates of origin: A role for ipr regimes in securing prior informed consent. In Access to Genetic Resources: Strategies for Sharing Benefits; Mugabe, J., Barber, C.V., Henne, G., Glowka, L., La Viña, A., Eds.; ACTS Press: Nairobi, Kenya, 1997; pp. 329-340.

34. Brunnengraeber, A.; Dietz, K.; Hirschl, B.; Walk, H. Interdisciplinarity in Governance Research; Garnet Working Paper No. 8; Warwick, UK.

35. Holm-Mueller, K.; Richerzhagen, C.; Taeuber, S. Users of Genetic Resources in Germany Awareness, Participation and Positions Regarding the Convention on Biological Diversity; Bundesamt fuer Naturschutz: Bonn, Germany, 2005; Volume 126, p. 120.

36. Kaufmann, D.; Kraay, A.; Mastruzzi, M. Governance Matters V: Governance Indicators for 1996-2005; The World Bank: Washington, DC, USA.

37. Ten Kate, K.; A Laird, S. The Commercial Use of Biodiversity-Access to Genetic Resources and Benefit-Sharing; Earthscan: London, UK, 1999.

38. Braga, C.A.P. Trade-related intellectual property issues: The uruguay-round agreement and its economic implications. In The uruguay Round and Developing Countries; Martin, W., Winter, L.A., Eds.; Cambridge University Press: Cambridge, UK, 1996; pp. 341-379.

(C) 2014 by the authors; licensee MDPI, Basel, Switzerland. This article is an open access article distributed under the terms and conditions of the Creative Commons Attribution license (http://creativecommons.org/licenses/by/3.0/). 